\title{
A patient with nerve abscesses due to leprosy
}

\author{
S H KARDAUN, B J VERMEER, D OVERBOSCH,* \\ G J ONVLEE $\dagger \&$ D L LEIKER $\ddagger$ \\ Departments of Dermatology, Infectious Diseases, ${ }^{*}$ Orthopaedics, $\ddagger$ \\ University Hospital, PO Box 9600, Leiden; $\uparrow$ The Department of \\ Dermatology, University Medical Centre, Amsterdam, The Nether- \\ lands
}

Accepted for publication 30 April 1985

\begin{abstract}
Summary A patient with borderline-tuberculoid leprosy who developed nerve abscesses along the line of cutaneous nerves is described. The treatment of choice is surgical removal of the abscess together with combination chemotherapy.
\end{abstract}

\section{Introduction}

A nerve abscess is a relatively rare complication of leprosy. Because it is not frequently encountered and Mycohacterium leprae does not grow on artificial culture media, the diagnosis may be missed unless the clinical picture is recognized. A patient with borderline tuberculoid leprosy, who developed such nerve abscesses, is described.

\section{Case report}

A 25-year-old Surinam-Javanese male noticed a hypopigmented hypaesthetic area above the right knee and subsequently a diagnosis of leprosy was made in Surinam. He received diamino-diphenyl sulphone (DDS)-monotherapy for $1 \frac{1}{2}$ years. He left Surinam and migrated to the Netherlands but did not have any therapy in the $2 \frac{1}{2}$ years before presenting at the Department of Dermatology, University Hospital, Leiden. His right leg showed a markedly depigmented, hypaesthetic macule just above the right knee. In addition there was a longitudinal swelling of rubbery consistency, starting from the depigmented area and running upwards for a distance of $10 \mathrm{~cm}$ (Figure 1).

A skin biopsy from the hypaesthetic macule showed a marked, partly granulomatous infiltrate with epithelioid cells, macrophages, and lymphocytes, 


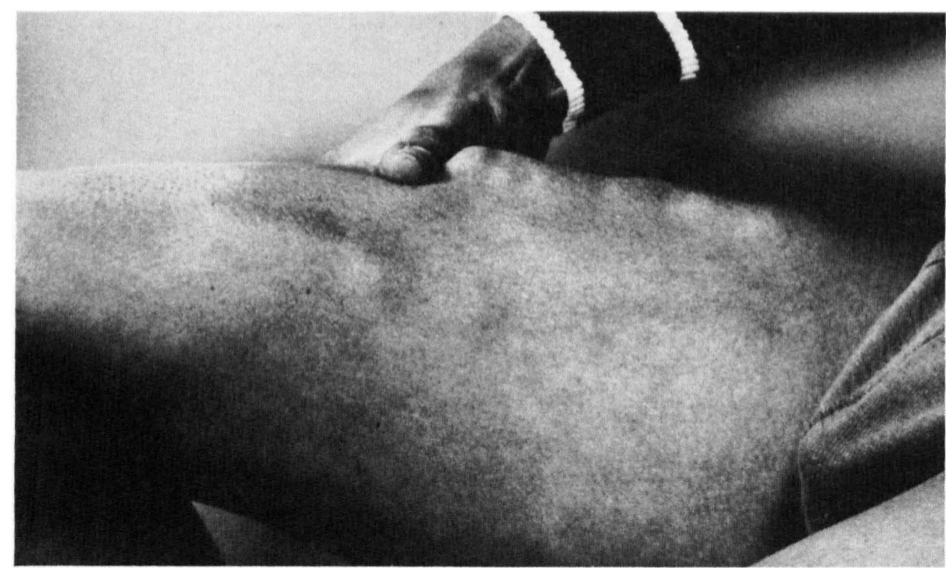

Figure 1. Abscesses due to leprosy along anterior cutaneous branches of the femoral nerve in the upper leg.

localized in the upper dermis, surrounding sweat glands and nerves. The ZiehlNeelsen stain did not show acid-fast bacilli. Earlobe and nose scrapings revealed no acid-fast bacilli. The lepromin reaction after 4 weeks was $8 \mathrm{~mm}$ in diameter; the PPD was negative. Cultures for M. tuherculosis, atypical mycobacteria, aerobic and anaerobic bacteria and fungi remained negative, as well as a mouse foot-pad test for $M$. leprae. Physical and laboratory examination and roentgenograms of chest, thoraco-lumbar spine and upper legs did not show abnormal findings. There was no evidence of calcification in the affected leg. As the diagnosis of borderline tuberculoid leprosy was confirmed, the patient was treated with the combination of $100 \mathrm{mg}$ DDS and $600 \mathrm{mg}$ rifampicin daily. In spite of treatment the rubbery swelling gradually progressed and a second, similar, swelling developed medially to the first one. After several months the swelling became fluctuating and pus was aspirated. Microscopical examination showed scanty acid-fast bacilli with granular forms.

As both abscesses were located in the course of the anterior cutaneous branches of the femoral nerve, the most likely diagnosis was an abscess of these nerves. The affected nerves were surgically removed in toto. There were no complications. The hypaesthetic area did not enlarge. Histological examination of the surgical specimen showed necrosis surrounded by epithelioid cells. Some remnants of nerve endings were found. There were no acid-fast bacilli. The combination therapy of dapsone and rifampicin was continued and in the followup period of over 1 year, no further abscesses were observed and the skin lesions did not show signs of activity.

\section{Discussion}

This patient had borderline tuberculoid leprosy. Nerve abscesses are uncommon 
and they are mainly found in patients with non-lepromatous leprosy. ${ }^{14} \mathrm{~A}$ few cases have been described in patients with lepromatous leprosy. ${ }^{58}$

Nerve abscesses due to leprosy have been reported from India and less commonly from Africa and America. ${ }^{1,2.4}$

The reaction to $M$. leprae that is responsible for the clinical form of the disease is said to be HLA-linked, ${ }^{9}$ but environmental factors or concomitant infections with other mycobacteria may also influence the clinical picture of leprosy. ${ }^{10}$ The pathogenesis of nerve abscesses is still speculative. An increase in cellular immunity against dead $M$. leprae may be responsible for the abscess formation. Depending on the presence of viable bacilli or their antigenic remnants in nerves and in skin, the nerves may become reactive, while the skin lesions may remain unaltered as happened in the patient described in this article.

The slow development of abscesses in the absence of constitutional symptoms, in association with an unchanging hypopigmented macule, excluded erythema nodosum leprosum.

Although nerve abscesses are an uncommon complication of leprosy, the typical localization along the course of cutaneous nerves, as in this case, should lead to a correct diagnosis. Other causes of cutaneous abscesses, such as atypical mycobacteria, should be ruled out. The treatment of choice is surgical removal of the abscess, together with combination chemotherapy.

\section{Acknowledgment}

We are grateful for the advice of Professor Dr E Scheffer, Laboratory of Pathology, State University, Leiden, The Netherlands.

\section{References}

1 Wade HW. Tuberculoid changes in leprosy, III. The pathology of a nerve abscess. Int J Lepr, 1934; 2: 293.

2 Browne SG. Nerve abscesses in African leprosy. Lepr Rev, 1965; 36: 55.

${ }^{3}$ Sehgal NV. Nerve abscesses in leprosy in Northern India. Lepr Rev, 1966; 37: 109.

${ }^{4}$ Singh G, Ojha D. Leprotic nerve abscesses. Dermatologica, 1969; 139: 109.

${ }^{5}$ Sato $S$. Nerve abscess in lepromatous leprosy. Report of a case, with a review of reports of nerve abscess in Japan. Int $J$ Lepr, 1956; 24: 408.

6 Job CK, Bhaktaviziam C. Nerve abscess in lepromatous leprosy. Report of a patient. Lepr Rev, 1967; 38: 243.

7 Enna CD, Brand PW. Peripheral nerve abscess in leprosy. Report of three cases encountered in dimorphous and lepromatous leprosy. Lepr Rev, 1970; 41: 175.

${ }^{8}$ Choudhury RSB, Srinivasan H. Nerve abscess in lepromatous leprosy. A case report and discussion of pathogenesis. Lepr India, 1977; 49: 330.

${ }^{9}$ de Vries RP, van Eerde W, van Rood JJ. HLA-linked control of M. leprae infections. Lepr Rev, 1981; 52 (suppl. I): 109.

${ }^{10}$ Stanford JL, Rook GAW, Samuel N, Madlener F, Khamenei AA, Nemati T, Modabber F, Rees RJW. Preliminary immunological studies in search of correlates of protective immunity carried out on some Iranian leprosy patients and their families. Lepr Rev, 1980; 51: 303. 